\title{
Mixed phase silicon oxide layers for thin-film silicon solar cells
}

\author{
Peter Cuony ${ }^{1}$, Duncan T.L. Alexander ${ }^{2}$, Linus Löfgren ${ }^{1}$, Michael Krumrey ${ }^{3}$, Michael \\ Marending ${ }^{1}$, Mathieu Despeisse ${ }^{1}$, Christophe Ballif ${ }^{1}$ \\ ${ }^{1}$ Ecole Polytechnique Fédérale de Lausanne (EPFL), Institute of Microengineering (IMT), \\ Photovoltaics and Thin Film Electronics Laboratory (PV-Lab), Rue Breguet 2, 2000 Neuchâtel, \\ Switzerland \\ ${ }^{2}$ Ecole Polytechnique Fédérale de Lausanne (EPFL), Interdisciplinary Centre for Electron \\ Microscopy (CIME), 1015 Lausanne, Switzerland \\ ${ }^{3}$ Physikalisch-Technische Bundesanstalt (PTB), Abbestr. 2-12, 10587 Berlin, Germany
}

\begin{abstract}
Lower absorption, lower refractive index and tunable resistance are three advantages of doped silicon oxide containing nanocrystalline silicon grains $\left(\mathrm{nc}^{-} \mathrm{SiO}_{\mathrm{x}}\right)$ compared to doped microcrystalline silicon, for the use as $\mathrm{p}$ - and n-type layers in thin-film silicon solar cells. In this study we show how optical, electrical and microstructural properties of $\mathrm{nc}_{-} \mathrm{SiO}_{\mathrm{x}}$ layers depend on precursor gas ratios and we propose a growth model to explain the phase separation in such films into Si-rich and O-rich regions as visualized by energy-filtered transmission electron microscopy.
\end{abstract}

\section{INTRODUCTION}

The tandem configuration with a hydrogenated amorphous silicon (a-Si) top cell and a hydrogenated microcrystalline silicon $(\mu \mathrm{c}-\mathrm{Si})$ bottom cell, also called the Micromorph configuration is a promising candidate for future large scale deployment of photovoltaics for electricity generation due to abundant source materials and scalable and low-cost deposition processes. Hydrogenated silicon oxide containing nanocrystalline silicon grains $\left(\mathrm{nc}^{\left.-\mathrm{SiO}_{\mathrm{x}}\right)}\right.$ has attracted much interest in the last years because of different applications in thin-film silicon solar cells: First, p-type nc-SiO ${ }_{\mathrm{x}}$ is an excellent window and anti-reflection layer, due to lower absorption coefficient and lower refractive index when compared to p-type $\mu \mathrm{c}-\mathrm{Si}$ layers [1]. Second, n-type nc-SiO ${ }_{x}$ can be used as intermediate reflecting layer, when inserted between two sub-cells of a tandem configuration, allowing for advanced light-trapping schemes [2-5]. Third, tunable resistance of $\mathrm{p}$ - and $\mathrm{n}$-type $\mathrm{nc}-\mathrm{SiO}_{\mathrm{x}}$ can help to reduce the impacts of shunts on the electrical cell parameters $[1,6]$.

\section{EXPERIMENTAL DETAILS}

The nc- $\mathrm{SiO}_{\mathrm{x}}$ layers are deposited at $200{ }^{\circ} \mathrm{C}$ from a gas mixture of $\mathrm{SiH}_{4}, \mathrm{H}_{2}$, and $\mathrm{CO}_{2}$ by plasma enhanced chemical vapor deposition, and $\mathrm{p}$ - and $\mathrm{n}$-type doping is achieved by adding $\mathrm{B}\left(\mathrm{CH}_{3}\right)_{3}$ and $\mathrm{PH}_{3}$, respectively. Fourier Transform Infrared (FTIR) absorption measurements are performed with a Nicolet 8700 system from Thermo on samples deposited on silicon wafers and absorption spectra are normalized with the layer thickness. Rutherford backscattering (RBS) and hydrogen forward scattering (HFS) measurements to determine $\mathrm{Si}$, O, and $\mathrm{H}$ contents are carried 
out by the Evans Analytical Group. The density is deduced from X-ray reflectometry performed with synchrotron radiation at the PTB four-crystal monochromator beamline at BESSY II [7]. The absorption coefficient $(\alpha)$ and refractive index $(n)$ are determined from fitting spectroscopic ellipsometry measurements to a Tauc-Lorentz dispersion model including a surface roughness layer. Two aluminum contacts are evaporated onto the samples, in order to measure the electrical in-plane dark conductivity $(\sigma)$ after 90 minutes annealing at $180{ }^{\circ} \mathrm{C}$ in vacuum. The crystalline fraction of the Si-rich phase (hence not taking into account the O-rich phase) is evaluated by Raman spectroscopy [8].

\section{RESULTS AND DISCUSSION}

Figure 1a shows infrared absorption peak of Si-O-Si stretching mode at $1050 \mathrm{~cm}^{-1}[9,10]$, which is increasing with increasing $\mathrm{CO}_{2} / \mathrm{SiH}_{4}$ precursor gas ratio due to increased oxygen content in the $\mathrm{nc}_{-} \mathrm{SiO}_{\mathrm{x}}$ films. From this absorption peak one can estimate the oxygen content and we found the best correlation to RBS measurements when using the proportionality constant $A_{\mathrm{SiO}}=1.48 \cdot 10^{19} \mathrm{~cm}^{-2}$ proposed by He et al. [11]. Figure $1 \mathrm{~b}$ demonstrates that oxygen incorporation is also enhanced by increasing $\mathrm{H}_{2}$ source gas dilution. To explain this effect, Iftiquar et al. [10] argue that in the plasma, atomic hydrogen inhibits the backward reaction of $\mathrm{CO}+\mathrm{O} \rightarrow \mathrm{CO}_{2}$ by forming $\mathrm{OH}$. Because highly reactive and electronegative $\mathrm{O}$ hardly leaves the plasma it is speculated that oxygen mainly reaches the growing $\mathrm{nc}_{-} \mathrm{SiO}_{\mathrm{x}}$ film in the form of $\mathrm{OH}$. In this context it is interesting to note that the hydrogen content does not correlate with $\mathrm{H}_{2}$ dilution in the plasma but shows a correlation to silicon content of the $\mathrm{nc}-\mathrm{SiO}_{\mathrm{x}}$ films which can be explained by free energy models predicting that $\mathrm{H}$ in $\mathrm{SiO}_{\mathrm{x}}$ films will be only bound to $\mathrm{Si}$ with an absence of $\mathrm{O}-\mathrm{H}$ bounds [12].
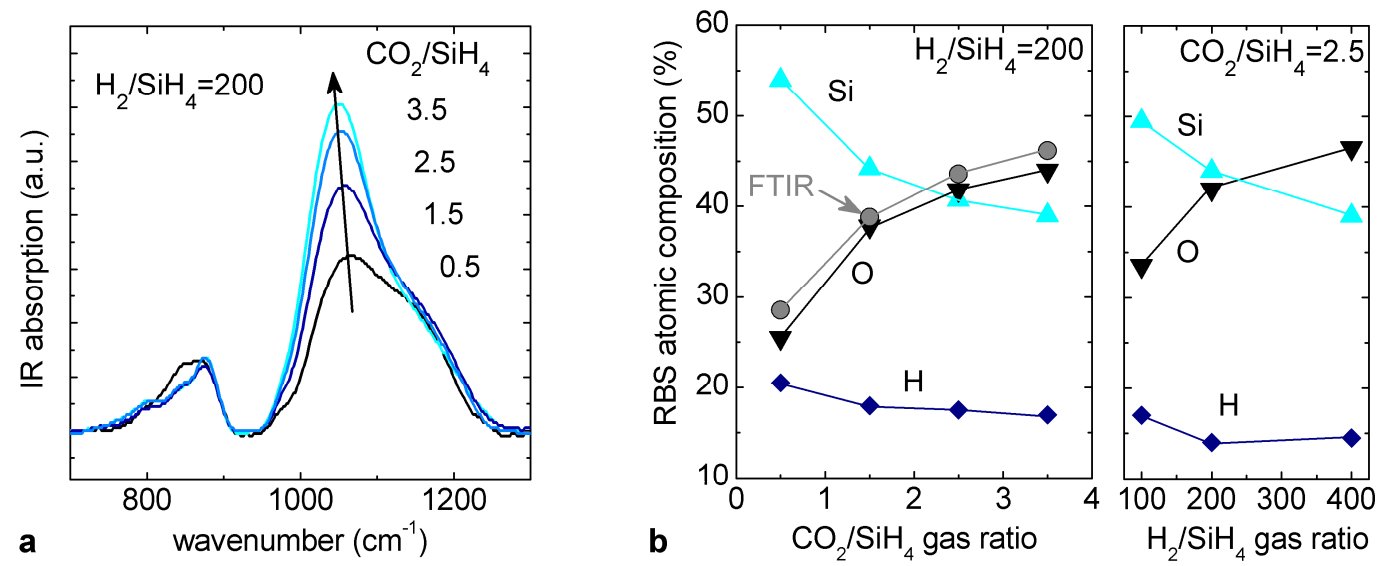

Figure 1. a) Infrared absorption peak of Si-O-Si stretching mode at $1050 \mathrm{~cm}^{-1}$ of $100 \mathrm{~nm}$ thick nc-SiO $\mathrm{x}_{\mathrm{x}}$ layers. b) Silicon, oxygen and hydrogen content measured by RBS and HFS for different source gas ratios and oxygen content calculated from FTIR measurements for comparison.

Figure 2a shows dark conductivity $(\sigma)$, silicon crystalline fraction $(S i R c)$ and absorption coefficient $(\alpha)$ of p- and n-type nc-SiO $\mathrm{x}_{\mathrm{x}}$ layers as a function of $\mathrm{CO}_{2} / \mathrm{SiH}_{4}$ gas flow ratio. In this experiment, the $\mathrm{H}_{2}$-dilution is set to 200 for $\mathrm{p}$-type layers and 100 for the $\mathrm{n}$-type layers, because in the $\mathrm{p}$-i-n configuration of $\mu \mathrm{c}-\mathrm{Si}$ cells it is common to use higher $\mathrm{H}_{2}$ dilution for the $\mathrm{p}$-layer because it grows on a $\mathrm{ZnO}$ substrate, with longer incubation phase compared to n-layer which 
grows directly on a $\mu \mathrm{c}-\mathrm{Si}$ layer, favoring the growth of microcrystalline material. For both $\mathrm{p}$ - and n-type layers, the dark in-plane conductivity is around $10 \mathrm{~S} \cdot \mathrm{cm}^{-1}$ for an oxygen free sample, and decreases rapidly with higher $\mathrm{CO}_{2} / \mathrm{SiH}_{4}$ gas ratio, due to an increasing amount of oxygen incorporated in the nc-SiO film. Furthermore, increasing $\mathrm{CO}_{2} / \mathrm{SiH}_{4}$ gas ratio reduces the Raman crystalline fraction of the $\mathrm{Si}$-rich phase in the $\mathrm{nc}-\mathrm{SiO}_{\mathrm{x}}$ layers, and decreases the optical absorption coefficient $\alpha$. Figure 2b shows the results obtained for different doping concentrations, ranging from $0 \%$ to $50 \%$, with a constant $\mathrm{CO}_{2} / \mathrm{SiH}_{4}$ gas ratio of 0.5 . p-type doping with trimethylboron (TMB) rapidly reduces the crystalline fraction of the silicon phase, and a maximum dark conductivity is obtained at $\mathrm{TMB} / \mathrm{SiH}_{4}=8 \%$. This is different for n-type doping with $\mathrm{PH}_{3}$, where dark conductivity is continuously increasing with increasing doping gas concentration as phosporous does not reduce the crystalline fraction of the silicon phase. This amorphizing effect of TMB limits the oxygen content in $\mathrm{nc}_{-}-\mathrm{SiO}_{\mathrm{x}}$ films to $\mathrm{x} \sim 0.5$ before the films become too resistive to be used in thin-film silicon solar cells. For n-type nc-SiO ${ }_{x}$ layers, where high phosphorous doping concentrations can partially make up for lower conductivity due to oxygen incorporation, we achieved $\mathrm{nc}-\mathrm{SiO}_{\mathrm{x}}$ films with $\mathrm{x} \sim 1$ which have still a transverse conductivity high enough for the use in thin-film silicon solar cells.
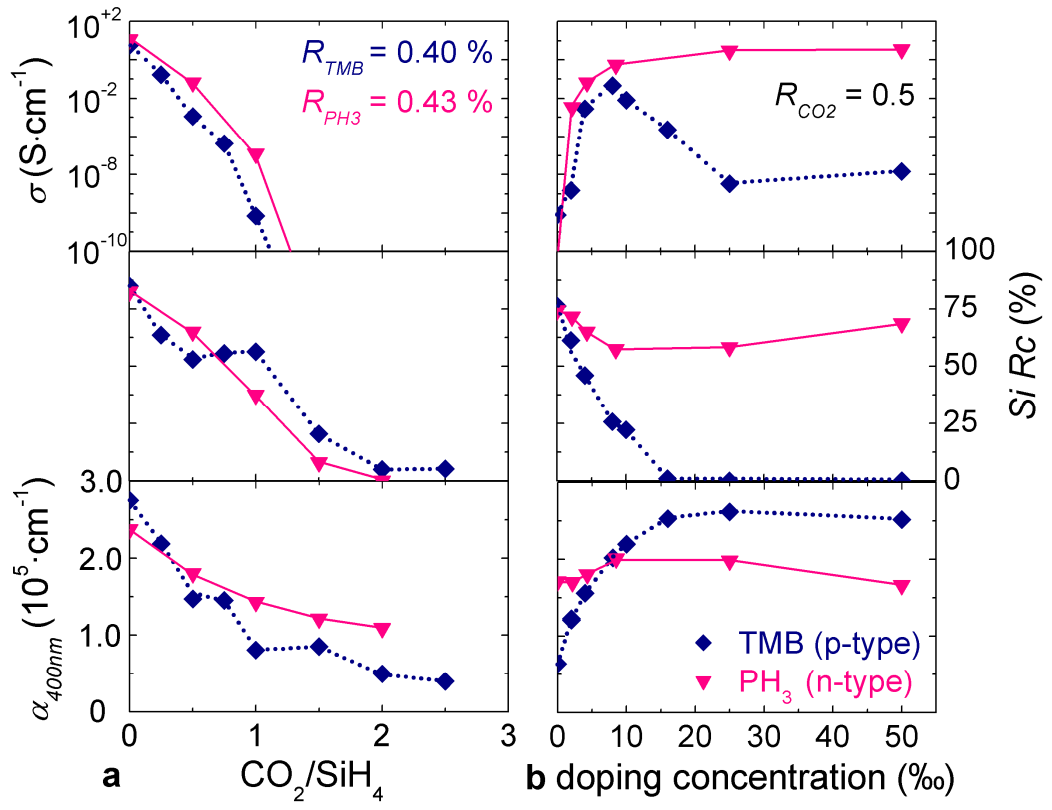

Figure 2. Evolution of dark conductivity $(\sigma)$, silicon Raman crystalline fraction $(S i R c)$ and absorption coefficient $(\alpha)$ of $\mathrm{p}$ - and n-type nc-SiO x layers deposited with different $\mathrm{CO}_{2} / \mathrm{SiH}_{4}$ gas ratios (a) and doping concentrations (b).

Figure $3 \mathrm{a}$ shows the decrease in dark conductivity due to air exposure of two nc- $\mathrm{SiO}_{\mathrm{x}}$ layers with different oxygen contents. The initial conductivity can be recovered by annealing the samples during 90 minutes at $180^{\circ}$ in vacuum. Water vapor penetrating into nano-pores of $\mathrm{nc}-\mathrm{SiO}_{\mathrm{x}}$ films is believed to be the major reason for this reversible in-plane conductivity degradation. Figure $3 \mathrm{~b}$ shows X-ray reflectometry measurements revealing a lower critical angle for $\mathrm{nc}_{-} \mathrm{SiO}_{\mathrm{x}}$ than for a-Si suggesting a lower density [13] and strengthening the hypothesis of nano-scale porosity in $\mathrm{nc}_{-} \mathrm{SiO}_{\mathrm{x}}$ layers. 

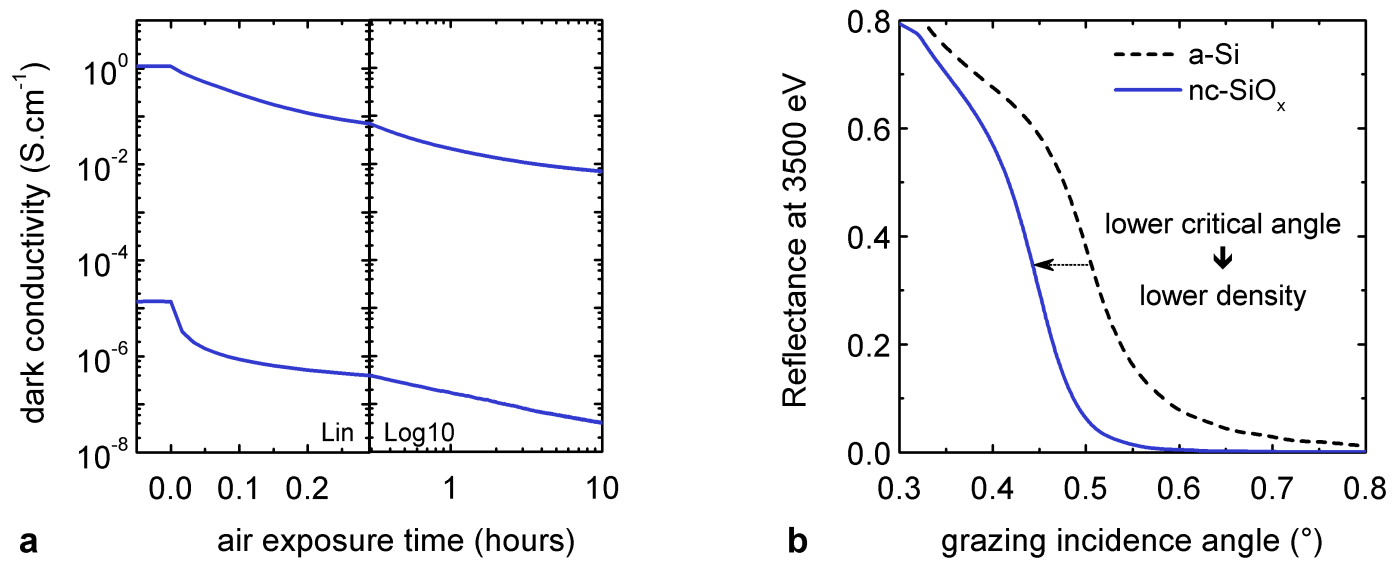

Figure 3. a) Decreasing dark conductivity due to air exposure of two different $100 \mathrm{~nm}$ thick nc$\mathrm{SiO}_{\mathrm{x}}$ layers. b) X-ray reflectometry measurements at $3500 \mathrm{eV}$ (far away from the Si absorption edge) indicating significantly less dense material for $\mathrm{nc}^{-\mathrm{SiO}_{\mathrm{x}}}$ when compared to a-Si material.

Figure 4 shows the nanostructure of the $\mathrm{nc}-\mathrm{SiO}_{\mathrm{x}}$ layer as visualized in plan-view by energyfiltered transmission electron microscopy $(\mathrm{Si}$-rich phase $=$ white; O-rich phase $=$ dark). The image is obtained using electrons from a $4 \mathrm{eV}$ window over the plasmon peak of silicon at $\sim 17.5 \mathrm{eV}$, after removal of the background contribution from the plasmon peak of $\mathrm{SiO}_{2}{ }^{14}$. While layers produced with low $\mathrm{H}_{2}$ dilution appear as homogenous $\mathrm{SiO}_{\mathrm{x}}$ mixture (Figure 4a), this technique reveals a pronounced phase separation on the nanometer scale into Si-rich regions surrounded by an O-rich material for samples that have been produced with a high $\mathrm{H}_{2}$ dilution (Figure 4b-c). The difference in silicon particle sizes between sample $\mathrm{b}$ and $\mathrm{c}$ is due to the different silicon content of the $\mathrm{nc}-\mathrm{SiO}_{\mathrm{x}}$ films. It is interesting to note that the homogenous

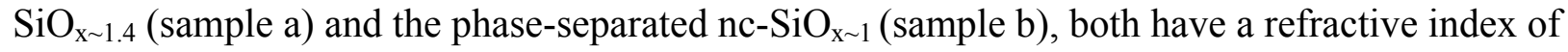
$\sim 1.8$ but different $\mathrm{SiO}_{\mathrm{x}}$ stoichiometry, which could be due to the increased nano-porosity in nc- $\mathrm{SiO}_{\mathrm{x}}$ samples with phase separation.
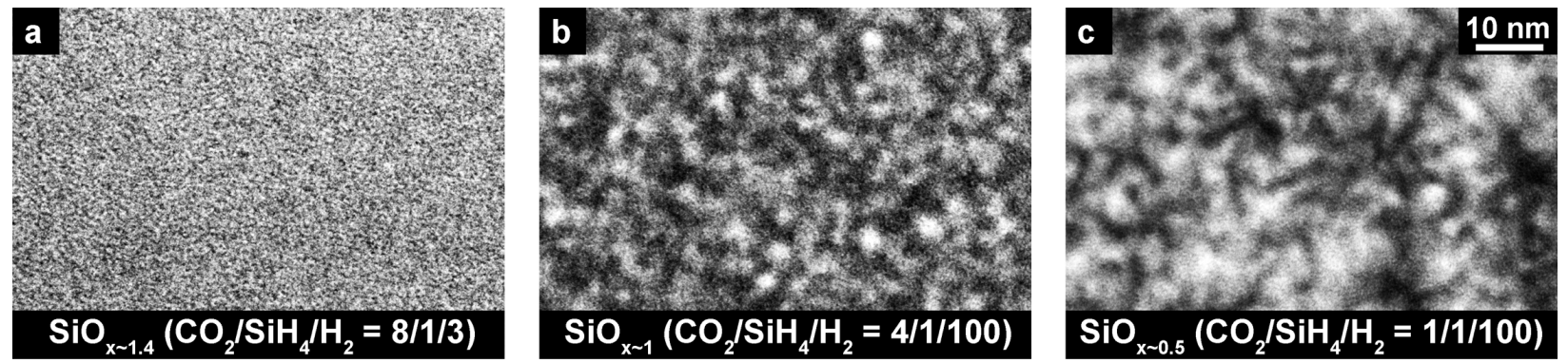

Figure 4. Plan-view phase separation visualized by energy-filtered transmission electron microscopy $\left(\mathrm{Si}\right.$ phase $=$ white) in $50-70 \mathrm{~nm}$ thick $\mathrm{nc}-\mathrm{SiO}_{\mathrm{x}}$ layers produced with different $\mathrm{CO}_{2} / \mathrm{SiH}_{4} / \mathrm{H}_{2}$ gas ratios.

Mixed-phase nc-SiO $\mathrm{x}_{\mathrm{x}}$ films have been studied previously, but the energetically favorable phase separation is usually obtained after high-temperature annealing of initially homogenous $\mathrm{SiO}_{\mathrm{x}}$ films [14-16]. In our case, we show that the phase separation is also possible at low substrate temperatures of $200{ }^{\circ} \mathrm{C}$, if produced with highly $\mathrm{H}_{2}$ diluted plasmas. This growth mechanism can be explained with the surface diffusion model [17], as developed for mixed- 
phase a-Si/ $\mu \mathrm{c}-\mathrm{Si}$ films. For low $\mathrm{H}_{2}$ dilution all the $\mathrm{Si}$ and $\mathrm{O}$ atoms arriving from the plasma stick to the surface leading to a homogenous $\mathrm{SiO}_{\mathrm{x}}$ film (Figure 5a), whereas high $\mathrm{H}_{2}$ dilution enables phase-separation by increasing adatom mobility via surface heating and passivation of surface dangling bonds (Figure 5b).
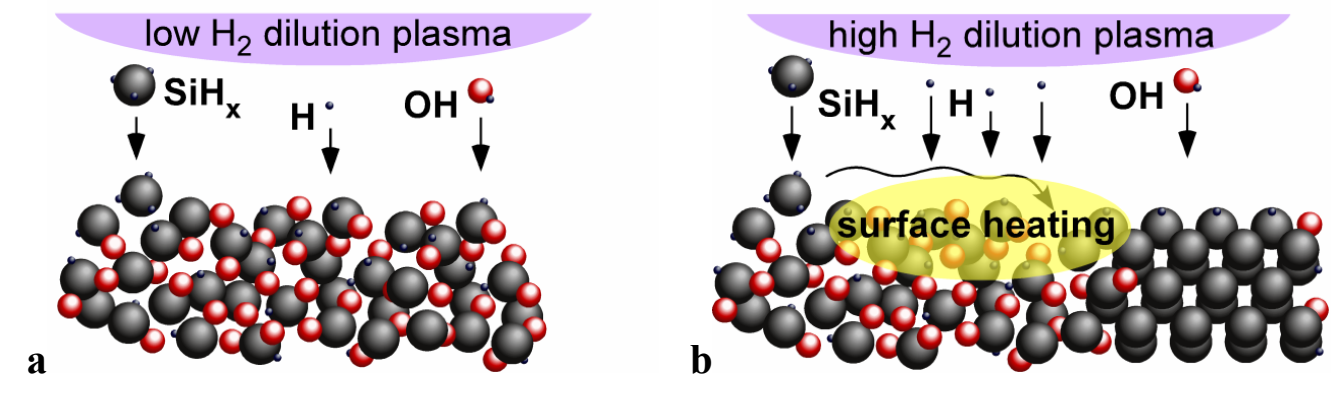

Figure 5. Surface diffusion model [17] with low adatom mobility in the case of low $\mathrm{H}_{2}$ dilution leading to homogenous $\mathrm{SiO}_{\mathrm{x}}$ material (a) and high adatom mobility due to surface heating and $\mathrm{H}$-bonding of surface dangling bonds in the case of high $\mathrm{H}_{2}$ dilution leading to $\mathrm{Si} / \mathrm{SiO}_{2}$ mixedphase structure (b).

\section{CONCLUSIONS}

In this contribution we have related precursor gas ratios to optical, electrical and microstructural characteristics of $\mathrm{nc}_{-} \mathrm{SiO}_{\mathrm{x}}$ films. We evidenced a possible nano-porosity in these films which makes them sensitive to air exposure. With energy-filtered transmission electron microscopy we demonstrated a phase separation within $\mathrm{nc}-\mathrm{SiO}_{\mathrm{x}}$ films into Si-rich and O-rich regions. $\mathrm{H}_{2}$ source gas dilution has been identified as a key parameter for the phase separation,

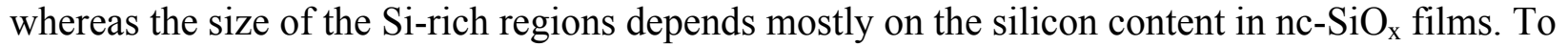
explain the phase-separation we used a modified surface diffusion model, originally developed for mixed-phase a-Si $/ \mu \mathrm{c}-\mathrm{Si}$ materials.

\section{ACKNOWLEDGMENTS}

The authors acknowledge support by the Swiss Federal Energy Office (Grant No. 101191).

\section{REFERENCES}

1. P. Cuony, M. Marending, D. T. L. Alexander, M. Boccard, G. Bugnon, M. Despeisse and C. Ballif, Appl Phys Lett 97 (21), 213502 (2010).

2. P. Buehlmann, J. Bailat, D. Domine, A. Billet, F. Meillaud, A. Feltrin and C. Ballif, Appl Phys Lett 91, 143505 (2007).

3. T. Grundler, A. Lambertz and F. Finger, physica status solidi (c) 7 (3-4), 1085-1088 (2010).

4. D. Dominé, P. Buehlmann, J. Bailat, A. Billet, A. Feltrin and C. Ballif, Phys Status Solidi-R 2 (4), 163-165 (2008).

5. P. Buehlmann, J. Bailat, A. Feltrin and C. Ballif, Photovoltaic Materials and Manufacturing Issues 1123 (2009). 
6. M. Despeisse, G. Bugnon, A. Feltrin, M. Stueckelberger, P. Cuony, F. Meillaud, A. Billet and C. Ballif, Appl Phys Lett 96, 073507 (2010).

7. M. Krumrey, M. Hoffmann, G. Ulm, K. Hasche and P. Thomsen-Schmidt, Thin Solid Films 459 (1-2), 241-244 (2004).

8. C. Droz, E. Vallat-Sauvain, J. Bailat, L. Feitknecht, J. Meier and A. Shah, Sol Energ Mat Sol C 81 (1), 61-71 (2004).

9. G. Lucovsky, J. Yang, S. S. Chao, J. E. Tyler and W. Czubatyj, Phys Rev B 28 (6), 32253233 (1983).

10. S. M. Iftiquar, J Phys D Appl Phys 31 (14), 1630-1641 (1998).

11. L. N. He, D. M. Wang and S. Hasegawa, J Non-Cryst Solids 261 (1-3), 67-71 (2000).

12. F. W. Smith and Z. Yin, J Non-Cryst Solids 137-138 (Part 2), 871-874 (1991).

13. L. G. Parratt, Phys Rev 99 (5), 1635-1635 (1955).

14. S. Schamm, C. Bonafos, H. Coffin, N. Cherkashin, M. Carrada, G. Ben Assayag, A. Claverie, M. Tence and C. Colliex, Ultramicroscopy 108 (4), 346-357 (2008).

15. G. Nicotra, S. Lombardo, C. Spinella, G. Ammendola, C. Gerardi and C. Demuro, Appl Surf Sci 205 (1-4), 304-308 (2003).

16. F. Iacona, C. Bongiorno, C. Spinella, S. Boninelli and F. Priolo, J Appl Phys 95 (7), 3723-3732 (2004).

17. A. Matsuda, Thin Solid Films 337 (1-2), 1-6 (1999). 